\title{
PROJETO MODERNO DE CIDADE: OS CONJUNTOS HABITACIONAIS DOS IAP NA GRANDE SÃO PAULO ${ }^{1}$
}

Housing Projects As Modern City Projects: The Housing Of The Iap In Great Sao Paulo From 1930 To 1964

\author{
Camila Ferrari \\ Instituto de Arquitetura e Urbanismo - Universidade de São Paulo \\ camilaferrari@ymail.com
}

\section{Resumo}

Neste trabalho propomos a análise dos conjuntos habitacionais empreendidos pelos Institutos de Aposentadoria e Pensões entre os anos 1933 e 1964 na então Grande São Paulo dentro da concepção de cidade moderna, ou seja, como projetos que, para além de moradias, sustentavam o caráter de projetos urbanísticos, inseridos na urbanização paulistana. Consideramos que é possível compreender que a cidade que se construiu na implantação destes conjuntos habitacionais foi a cidade moderna, em contraste com a urbanização paulistana geral, que intentava ser moderna, colocando, porém em segundo plano a dimensão social da arquitetura, fator fundamental do projeto moderno.

\section{Palavras-chave}

Institutos de Aposentadoria e Pensões, Cidade Moderna, Urbanização de São Paulo

\section{Abstract}

In this work we propose the analysis of the housing undertaken by Institutos de Aposentadoria e Pensões between the years 1933 and 1964 in those days Greater São Paulo within the design of the modern city, in other words, as projects which beyond housing, sustained the nature of urban projects, embedded in the urbanization of São Paulo. We consider that the city that was built from the implementation of such housing projects was the modern city, in contrast to the general urbanization of São Paulo, which intended to be modern, however setting in the background the social dimension of architecture, key factor of the modern project.

\section{Keywords}

Institutes of Retirement and Pensions, Modern City, Urbanization of São Paulo

\footnotetext{
${ }^{1}$ Este artigo é parte da pesquisa de Mestrado "Projetos de Habitação Popular como Projetos de Cidade Moderna: Os Conjuntos Habitacionais dos IAP da Grande São Paulo de 1930 a 1964", realizada no Programa de Pós-Graduação em Arquitetura e Urbanismo no IAU-USP.
} 
O estudo dos percursos de diferentes arquitetos, estudiosos e urbanistas ao longo da história do final do século XIX e início do século XX nos possibilita estabelecer pontos comuns entre as diversas abordagens consideradas modernas, dentre eles a racionalização, a produção em série, o zoneamento, as preocupações quanto a salubridade, a circulação, a relação entre o homem e o meio. No entanto, a grande questão que perpassa estas proposições e que conecta arquitetura e urbanismo em um mesmo pensamento, ou seja, aquela que é a base da cidade moderna e se confirma como razão social da arquitetura é a habitação. A moradia é assim assumida no urbanismo moderno como fator fundamental para a reorganização da cidade, o mínimo elemento habitável a partir do qual naturalmente se estabeleceriam as demais funções urbanas.

\section{A Urbanização de São Paulo}

Interessa para os fins deste artigo o desenvolvimento urbano ocorrido a partir do crescimento da atividade cafeeira por volta de 1870, que altera significativamente o conjunto da cidade de São Paulo até então restrita à ocupação da colina histórica, até a década de 1950, compreendendo o período diretamente anterior e coetâneo atuação dos IAP.

A primeira região favorecida pela produção maciva do café foi o Vale do Paraíba, afetando apenas parcialmente a cidade de São Paulo. Segundo Morse (1970) a terra ao redor da cidade era infértil o que inicialmente bloqueou o avanço do café, porém, com o aumento da produção após 1822, a cultura deu um salto em direção às terras férteis a Norte e a Oeste, se espalhando rapidamente para Minas Gerais e São Paulo, numa região que possuía vantagens sobre a área produtiva inicial por não ser montanhosa e apresentar um tipo de solo bastante fértil, a "terra roxa". Com o crescimento da cultura do café ocorre concomitantemente a aceleração da vida urbana de São Paulo. Em 1867, é concluída a São Paulo Railway, a "E.F. SantosJundiaí", ligando o porto de Santos até o planalto paulista. A partir de 1868 novas ferrovias seriam construídas, ligando o interior e outros estados à São Paulo Railway, ou seja, à cidade de São Paulo, impulsionando o crescimento e o adensamento da cidade, de modo que já na última década daquele século esta ascenderia à condição de núcleo da região economicamente mais dinâmica do país.

As primeiras atitudes no sentido de transformar a cidade de modo que atendesse às novas necessidades da população crescente foram tomadas entre 1872 e 1875, destacando-seo calçamento das ruas triângulo histórico - o núcleo principal conformado por três ruas que ligavam os mosteiros do Carmo, de São Francisco e de 
São Bento no alto da colina - e a abertura ou o alargamento de vias. Em 1885 se inicia com capital privado, a construção do Viaduto do Chá, ligando o triângulo tradicional ao Morro do Chá, como símbolo do progresso rumo a Oeste, que não só permitiu a transposição da várzea como ocasionou a valorização desta região da cidade, incentivando a ocupação imobiliária no vetor (CAMPOS, 2002).

Após a implementação do governo republicano, as intervenções urbanísticas tornaram-se prioridade e o setor de obras se concentrou na construção de prédios institucionais e em saneamento, com o estabelecimento da polícia sanitária, responsável por realizar vistorias e intervenções especialmente nos cortiços, com desinfecção das habitações e vacinação. Também é promulgado novo Código Sanitário em 1894, sistematizando exigências quanto à urbanização, como a largura mínima de ruas e as relações entre estas e altura dos edifícios e, ainda, as requisições quanto à salubridade das construções (BONDUKI, 1998), proibindo as habitações coletivas e indicando que as vilas operárias ficassem fora da aglomeração urbana.

Durante a gestão Antonio Prado, segundo Campos (2002, p.103), as "iniciativas parciais que caracterizaram os primeiros anos do século XX evoluíram para um conjunto de propostas de maior alcance", tomando forma no "Plano de Melhoramentos da Capital" elaborado em 1911 por Victor da Silva Freire. Sobre o projeto de Victor Freire, Simões Junior (In Espaço\&Debates, 1991, p.73) destaca a intenção de uma visão mais globalizada, apoiada "sobre o tripé analítico do viário, do estético e do sanitário"; a crítica ao urbanismo haussmanniano em favor de um modelo mais culturalista como o de Sitte; a incorporação de "noção da Ringstrasse vienense ou de avenida circular contornando o centro da cidade", no interior da qual seria previsto apenas o trânsito de pedestres; o projeto das áreas de expansão e novos bairros como cidades-jardins e a reserva de áreas verdes. O plano, porém, desconsidera "a problemática urbano-social, relacionada principalmente à precariedade das condições de moradia".

Ainda em 1911 é solicitado ao urbanista francês J. A. Bouvard um novo plano para a região do Vale do Anhangabaú. O projeto elaborado no mesmo ano era próximo daquele de Victor Freire, com o traçado orgânico e pitoresco dos arruamentos, com desvio do trânsito do centro baseado em um anel viário que contornava a colina central e um anel mais externo paralelo ao primeiro, prevendo ainda a implantação de parques ao redor da colina histórica e um centro cívico. 0 Parque do Anhangabaú seria construído conforme o projeto de Bouvard, conciliando arquitetura e paisagismo de modo a conformar um grande conjunto urbano. 
As ações permaneciam direcionadas à região central, com afastamento da classe popular e proibição de cortiços, mas também propondo novas normas para habitação operária. Acreditava-se na moradia operária saudável como forma de extirpar os males da pobreza, buscando-se padrões europeus como as leis para habitações-modelo e o higienismo, e determinando os lugares dos ricos e os lugares dos pobres no espaço da cidade. Embora a legislação ditasse os padrões e incentivasse a construção de vilas operárias, o cenário acabou alicerçando o mercado de habitação popular em conjuntos de pequenas casas construídas em sua maioria por locatários rentistas, cujas unidades adquiriram padrões baixíssimos, aproximandose da imagem dos cortiços, sendo alugadas por valores que tomavam grande parte dos salários dos trabalhadores. Assim, os "bairros operários" do Brás, Mooca e Barra Funda, foram especialmente tomados por esse tipo de construção que abrigava os trabalhadores das muitas indústrias que ali se localizavam, dada a precariedade ou ausência de meios de transporte que pudessem ligar eficazmente estes bairros e outros locais da cidade.

Alguns poucos empreendimentos, todavia, apresentavam um padrão construtivo mais racionalizado, que permitia baratear o custo final das moradias, sem acarretar em aluguéis maiores ou prejuízo para a higiene dos moradores. A maior exceção dentre as diversas vilas operárias construídas no período é a Vila Maria Zélia, construída pelo industrial Jorge Street em 1916 no Belenzinho, para alojar os operários da Companhia Nacional de Tecidos de Juta. A vila foi construída como um verdadeiro bairro, contando, além das moradias, com uma série de equipamentos como igreja, mercearia, clube e escolas, com instrução obrigatória para os filhos dos funcionários (MORSE, 1970).

Em 1912 empreendedores paulistas associados ao capital inglês formaram a City of São Paulo Improvements and Freehold Land Company Limited, a Companhia City, que seria um dos mais importantes agentes do processo de urbanização da cidade possuindo "o equivalente a $37 \%$ da área então urbanizada de São Paulo" (SIMÕES JUNIOR In Espaço\&Debates, 1991, p.73) e implantando aí loteamentos para as classes média e alta, apoiados em princípios do urbanismo moderno. Os novos loteamentos, entre os quais estão o Jardim América, o Pacaembu e o Alto de Pinheiros, adquiriram o aspecto e a nomeação de "bairros-jardim", com uso unicamente residencial, infraestrutura e grandes avenidas prevendo a integração com o restante da cidade, sendo também características as ruas curvas internas ao loteamento, os lotes de grandes dimensões com recuos frontais e laterais obrigatórios e as quadras com áreas verdes internas, dispondo de arborização e passeios. 
Em 1924 Ulhôa Cintra apresenta um projeto para a área central de São Paulo com circuitos perimetrais sucessivos, apoiados em vias radiais. O "Perímetro de Irradiação" era um anel viário que contornava o centro histórico sem adentrá-lo, atrelando a perspectiva de crescimento urbano à expansão da área central e concordando funcionalidade e monumentalidade. Entre 1927 e 1930 toma corpo o "Plano de Avenidas" de Francisco Prestes Maia, em associação com Ulhôa Cintra. No plano, que parte da priorização de aspectos viários e de transporte e da conformação de um sistema de comunicações eficiente,

os princípios da centralização - herdados da capital construída em torno da economia cafeeira - e de expansionismo - ligado ao desenvolvimento produtivo e industrial - seriam conciliados pela combinação de um modelo radial-perimetral indefinidamente ampliável e a organização de seu movimento centrípeto pelo perímetro de irradiação. (CAMPOS, 2002, p.396397).

Uma série de ideologias estava embutida nas disposições de projeto, tais como a elitização das áreas centrais, uma vez que o perímetro de irradiação atravessava alguns dos principais bolsões de pobreza adjacentes à área central, desarticulando-os; o ideal de progresso simbolizado pela própria expansão física da cidade, aqui representado pelas radiais; a questão do embelezamento conjugada à preocupação viária, promovida pela articulação de rotatórias, praças e conjuntos arquitetônicos monumentais. Apesar de demonstrar grande conhecimento sobre as discussões internacionais referentes à habitação popular, Maia não chega a elaborar uma proposta de provisão habitacional dentro do Plano de Avenidas, resumindo-se a elucidar a possibilidade de construção de casas populares nas áreas públicas junto à várzea do Tietê ou da organização de bairros-jardim nas regiões próximas à área central de onde fossem retiradas ferrovias e indústrias (MAIA, 1930).

Em 1930 Anhaia Mello é nomeado prefeito de São Paulo e dentre suas realizações destaca-se o projeto de zoneamento da cidade. O zoning proposto "baseava-se na restrição ao uso indiscriminado da propriedade urbana, criando distritos com padrões diferenciados de ocupação e edificação" de modo a garantir "a integridade estética urbana e a manutenção dos valores imobiliários, evitando a especulação". Mello propunha a limitação, a regulação e o equilíbrio do crescimento urbano, defendendo um "zoneamento protetor e regulador" antes de aderir a um zoneamento funcional (CAMPOS, 2002, p.469). Mello demonstrou preocupação quanto à legalidade na periferia da cidade, pois a falta de reconhecimento de loteamentos e edificações gerava o problema da falta de serviços públicos, que só podiam ser URBANA, V.6, no 8, jun.2014 - Dossiê: Cidade e Habitação na América Latina - CIEC/UNICAMP 
implantados em locais oficialmente reconhecidos. A partir de 1932 se permitiria o reconhecimento de edificações em loteamentos até então ilegais, conforme julgamento da Diretoria de Obras Municipais, que analisava e indicava as mudanças necessárias para a aprovação.

Fabio Prado assume a prefeitura entre os anos de 1934 e 1938. Destacam-se no período as obras de caráter sócio-cultural, dentre as quais as primeiras implantadas foram os parques infantis.

O objetivo maior destas instituições era contribuir para a formação social e moral das crianças, complementando a educação dada pela escola e pela família. Em muitos casos, porém os parques foram estrategicamente instalados em bairros absolutamente carentes de escolas, assumindo, portanto, uma parcela do papel destas instituições. (SAMPAIO, 1999, p.48).

Na gestão de Fabio Prado, foi montado um mapa da capital com 53 parques, dos quais apenas quatro foram construídos em seu governo, incluindo a reformulação do Parque Dom Pedro II, sendo outros três executados na gestão seguinte por Prestes Maia e os demais não implantados. Também durante sua gestão iniciou-se a construção da Biblioteca Municipal e do Estádio Municipal, ambos finalizados na prefeitura de Prestes Maia.

Em 1938 Prestes Maia é nomeado prefeito e prossegue à implementação do Plano de Avenidas, com a retificação do rio Tietê e a construção de inúmeras novas vias, além da revisão e implantação do perímetro de irradiação. "As diretrizes adotadas no novo trajeto eram eminentemente pragmáticas e utilitárias, substituindo motivações estético-monumentais presentes em traçados anteriores" (CAMPOS, 2002, p.582). Do plano, cuja função primordial era adequar a cidade a uma melhor circulação, tanto de veículos quanto de pessoas, "resultou um centro verticalizado, adensado e a continuação de um padrão periférico que as linhas férreas já haviam definido e que a flexibilidade trazida pelo ônibus multiplicou" (SAMPAIO, 1999:22). O ônibus permitiu também a reorganização e reestruturação das relações entre bairros, incluindo aqueles que não eram atravessados pelas ferrovias, além da ampliação das relações no núcleo central com os municípios do entorno.

O prefeito Lineu Prestes, em 1950, encomenda um estudo à International Basic Economy Corporation (IBEC), órgão presidido por Nelson Rockfeller, que prestava consultoria técnica a países em desenvolvimento. Do estudo resulta um relatório elaborado pelo urbanista americano Robert Moses, o "Programa de Melhoramentos Públicos para São Paulo", do qual constavam: 
a) uma planta geral e um plano de zoneamento; b) um sistema de artérias de tráfego; c) transporte coletivo; d) parques e praças de recreio; e) retificação do rio Tietê e saneamento e utilização das várzeas; f) engenharia sanitária; e g) sugestões sobre métodos de financiamento para a realização de obras e serviços públicos." (IBEC, 1950, p. $8^{2}$ apud SOMEKH; CAMPOS In SOMEKH; CAMPOS, 2002, p.85).

São elaboradas propostas para zoneamento, sistema de transportes e viário, saneamento e áreas verdes. O resultado apresenta-se, contudo, conforme Somekh e Campos (In SOMEKH\&CAMPOS, 2002) mais como um "conjunto de recomendações", com poucos mapas e ausência de desenhos detalhados, bem como de uma planta de zoneamento.

Em 1956 tem início o estudo intitulado "Estrutura Urbana da Aglomeração Paulistana", elaborado pela "Sociedade para Análises Gráficas e Mecanográficas Aplicadas aos Complexos Sociais", a SAGMACS, que mais que apresentar um levantamento, consistiu num "diagnóstico urbanístico das condições sociais e estruturais da cidade de São Paulo e seus municípios vizinhos" (CESTARO, 2009, p.148). O estudo torna-se a maior pesquisa empírica realizada até aquele momento no país, sem, contudo, pretender a elaboração de um plano de obras urbanísticas.

\subsection{A apropriação parcial do projeto moderno}

Morse (1970) afirma que nos países latino-americanos a urbanização foi mais rápida que a industrialização e, no entanto, o próprio autor considera que a cidade de São Paulo constituía uma exceção a esta regra, dado que desde 1890 já existissem aí indústrias e se configurasse um incipiente processo de modernização urbana. Esta modernização se mostrava, porém, ainda vinculada ao capital agrário e obedecia aos princípios por ele ditados, uma vez que os cafeicultores estabeleciam também residências urbanas, controlando não apenas o negócio do café desde a produção no campo até a comercialização na cidade, como também a urbanização. Para Campos (2002:32) o fato de o urbanismo surgir "vinculado à problemática da modernização em um país agrário e não como resposta a requisitos da cidade industrial", conformou posições anti-industrialistas por parte daqueles que detinham o controle dos padrões de urbanização e modernização, a elite oligárquica vinculada à economia cafeeira.

Essa configuração levou a obras que visavam principalmente atender a questões sanitárias e de embelezamento da região central, área destinada à utilização pela elite e de onde se procurou afastar a população pobre e negra, sem a incorporação de medidas que de fato possibilitassem a melhoria das condições de vida

\footnotetext{
2 IBEC. Programa de Melhoramentos Públicos para a cidade de São Paulo. New York, 1950.

URBANA, V.6, no 8, jun.2014 - Dossiê: Cidade e Habitação na América Latina - CIEC/UNICAMP
} 
daqueles economicamente desfavorecidos e diminuíssem a disparidade entre ricos e pobres.

Esta inércia da estrutura social, no sentido da manutenção das condições inerentes a cada patamar, é apontada por autores como Campos (2002) como uma das principais causas da apropriação parcial dos conceitos modernizadores do espaço urbano que abarcavam por princípio questões sociais, tais como o atendimento às necessidades de moradia, equipamentos e serviços coletivos, e integração das classes trabalhadoras, não incorporadas no esquema de urbanização-industrialização paulistano. Outra limitação à modernização se deu ainda pela questão fundiária marcada pelas condições patrimonialistas herdadas do ambiente agroexportador e latifundiário, cuja alteração era tão atravancada por interesses particulares quanto a alteração das estruturas sociais.

A presença de um "Estado nacionalista benfeitor" e incentivador da industrialização (GORELIK In MIRANDA, 1999), e a atuação de prefeitos engajados, associadas à possibilidade de ação de arquitetos e urbanistas adeptos do discurso moderno, dada principalmente pelo Estado Novo varguista, configuraram um quadro de constantes obras urbanísticas no sentido de fazer crescer e desenvolver a cidade de São Paulo. Contudo, este ímpeto modernizador seria ainda reduzido pela manutenção das estruturas sociais que, embora com o fim do poder oligárquico e a confirmação de novos personagens sociais como a classe trabalhadora e a classe média, admitia a superioridade das elites agrária e industrial em detrimento das massas, e pela questão da terra urbana, com grande expansão periférica da cidade de São Paulo associada à moradia autoconstruída pela população trabalhadora.

A partir de 1950, conforme exposto por Leme (1999), os planos regionais assumem papel importante na organização ou remodelação das cidades brasileiras e também em São Paulo se nota essa tendência, com a preocupação quanto à extensão dos transportes coletivos, representada principalmente pelos projetos para uma rede metropolitana, e a atuação de estrangeiros como Moses e Lebret na confecção de estudos que possibilitassem a elaboração de planos de conjunto regionais. Ainda mais uma vez, é possível perceber a movimentação de forças no sentido de garantir a mesma "pirâmide social" e o valor da terra, por exemplo, pela refutação por parte da própria administração municipal do estudo elaborado pela SAGMACS, que revelou as precárias condições da periferia paulistana em contraste com os bairros da elite.

Percebe-se, assim, que a aspiração paulistana ao moderno, pela permanência de fatores contrários ao próprio projeto moderno, entre eles a inércia elitista da estrutura social e o patrimonialismo correspondente na questão fundiária, resultou em 
São Paulo numa apropriação apenas parcial dos princípios modernizadores, o que, ao longo dos anos, produziu uma cidade que se pretendia moderna, mas que não implementava integralmente a modernização, por justamente colocar em segundo plano a dimensão social da arquitetura, fator fundamental do projeto moderno caracterizado pela extensão do alojamento a toda população.

\section{Os Institutos de Aposentadoria e Pensões}

Para regularizar a situação do Brasil tanto internamente quanto no cenário internacional, as primeiras atitudes do presidente Getúlio Vargas após a Revolução de 1930 foram no sentido de estancar a crise econômica por ocasião da quebra da bolsa de valores de New York em 1929, que desmantelara o mercado mundial, não sendo o brasileiro uma excessão, prejudicado pela desvalorização internacional do produto base de sua economia, o café. Assim, uma vez que o café ainda era a base da economia, o Estado não pôde prescindir do setor, mas passou a incentivar a diversificação da produção agrícola, atendendo às reivindicações dos agricultores desvinculados do empreendimento cafeeiro, e deu início a um processo de despolarização da economia em torno do café, passando a incentivar também os investimentos na indústria, elemento-chave para sua proposta de desenvolvimento nacional.

O governo Vargas compreende que nenhum dos grupos participantes do poder político o detinha com exclusividade ou podia oferecer as bases da legitimidade do Estado: a elite cafeeira porque fora deslocada do poder político, os setores menos associados à exportação porque não se encontravam vinculados aos centros básicos da economia, as classes médias, porque não possuíam "autonomia política frente aos interesses tradicionais em geral" e a elite industrial, que ainda se firmava como influência político-econômica (WEFFORT, 1980, p.50).

Deste modo, o poder conquistado pelos revolucionários [...] só encontraria condições de persistência na medida em que se tornasse receptivo às aspirações populares. [...]. Aparece na história brasileira um novo personagem: as massas populares urbanas, [...] a única fonte de legitimidade possível ao novo Estado brasileiro. (WEFFORT, 1980, p.50-51, grifo do autor).

É desta forma que o governo Vargas aponta um novo setor da sociedade como fundamental para a legitimação de seu governo, distinguindo no trabalhador o "novo homem brasileiro" que representaria a imagem da nação. No operariado se reconhece a base da indústria nacional que o Estado procurava incentivar, sendo admitida a 
importância de prover as condições necessárias para a reprodução da força de trabalho, como o salário mínimo e a assistência à saúde. Somente assim se formariam cidadãos capazes de oferecer seu trabalho na condução da indústria brasileira, sendo inclusive consumidores. Entre outros fatores, está também a preocupação em reorganizar as relações econômicas juntamente com a questão social, notoriamente através da criação da carteira profissional obrigatória e da concepção dos Institutos de Aposentadoria e Pensões (IAP), órgãos a cuja função principal de reorganizar a questão previdenciária seriam acrescidos outros papéis sociais.

É em meio à proposta de reorganização social que a habitação aparece como caminho para modificar as condições da classe trabalhadora, introduzindo novos hábitos e um modo de vida moderno, que romperiam com o atraso do país expresso no subdesenvolvimento, na ignorância, na injustiça social e nas práticas de produção arcaicas e de baixa qualidade. A moradia passa a ser vista como item básico da reprodução da força de trabalho e, portanto, como fator econômico na estratégia de industrialização do país e, além disso, como elemento na formação ideológica, política e moral do trabalhador, logo, decisiva na formação do novo homem trabalhador brasileiro (BONDUKI, 1998).

O modelo adotado até então, de casas operárias produzidas pelo setor privado, é questionado pelo Estado, que logo põe fim aos privilégios garantidos aos investidores, passando ele próprio a orientar a construção de moradias, marcando o início da produção de habitação social no Brasil. Essa produção ocorreria por caminhos diversos, dentre os quais destacamos a atuação dos IAP.

Os Institutos de Aposentadoria e Pensões foram formulados em 1933 com caráter autárquico: após sua constituição legal pelo aparelho estatal deveriam ser organizados pelos próprios empregadores e, principalmente, pelos trabalhadores, a maioria sindicalizada, e o controle de sua gestão seria feito através do Ministério do Trabalho, Indústria e Comércio (MTIC), cujas atribuições incluíam orientar e supervisionar a previdência social, inclusive pela nomeação dos presidentes dos vários IAP.

A origem dos Institutos remete, contudo, a 1923, quando, na presidência de Arthur Bernardes é aprovada a Lei Elói Chaves (Decreto n 4.682 de 24 de janeiro de 1923), determinando a criação de uma Caixa de Aposentadoria e Pensões (CAP) para os empregados das ferrovias. Este é considerado o ponto de partida da previdência social brasileira, pois a partir de então outras categorias profissionais foram incorporadas ao regimento da Lei Elói Chaves, formulando suas próprias CAPs, que estruturaram o sistema previdenciário brasileiro, até então a cargo dos próprios 
empregados. As CAPs estruturavam-se basicamente pela criação de um fundo de caráter tripartido entre empregado, empregador e Estado, que vinha da abdicação das partes de uma parcela da renda a que teriam direito segundo os rendimentos de cada empresa, fundo este que seria revertido ao trabalhador no momento de sua aposentadoria ou quando fosse necessário o pagamento de pensão. Em 1930 já havia 47 Caixas, contando com cerca de 140 mil associados.

A partir de 1933, o governo Vargas elaboraria os IAP, sendo o primeiro deles o Instituto de Aposentadoria e Pensões dos Marítimos (IAPM). Seu caráter era semelhante ao das CAPs, mas diferentemente delas os IAP abrangeriam as categorias profissionais como um todo, independentemente das empresas contratantes. Os benefícios assegurados aos associados, com algumas peculiaridades a cada Instituto, incluiam aposentadoria, pensão em caso de morte, assistência médica e hospitalar, e socorros farmacêuticos.

Os fundos deveriam ser utilizados de acordo com um "'regime de capitalização', pelo qual os recursos arrecadados compulsoriamente de assalariados e empregadores deviam ser aplicados em investimentos que garantissem o aumento do fundo" (BRASIL, 1933, Art. 23). Seriam criados em seguida: o IAPC (Comerciários), o IAPB (Bancários), o IAPI (Industriários), o IAPETC (Empregados em Transportes e Cargas) e outros, todos basicamente sob a mesma organização empresa - empregado - associado, mesmas fontes de receita e com relativa variação quanto à aplicação dos recursos e benefícios oferecidos.

Embora desde 1930 fosse possível e legal a aplicação de fundos previdenciários no setor da habitação popular, seria somente em 1937, com o Decreto $\mathrm{n}^{\circ} 1.749$, que se buscaria criar condições para uma atuação mais vigorosa dos IAP na área, através da regularização de suas Carteiras Prediais. Dentro das burocracias atuariais dos IAP, conforme afirma Bonduki (2011), havia quem considerasse a inversão dos recursos em moradias populares uma forma pouco proveitosa de aplicação, uma vez que se por um lado o retorno financeiro era garantido, por outro, era necessário despender uma determinada quantia com as construções. No entanto, a inversão imobiliária ainda era considerada uma atividade segura de capitalização, de modo que a ação de reverter os fundos aos próprios trabalhadores através de moradias alugadas permaneceu nos Institutos, mesmo garantindo uma rentabilidade pequena, apoiada por presidentes engajados e pelos profissionais envolvidos nos setores de engenharia de cada IAP, que entendiam como função social o provimento da moradia econômica aos associados. Essa ambiguidade persistiria durante toda a existência dos IAP. 
O desafio de produzir moradias saudáveis, acessíveis e rentáveis foi

o grande propulsor do desenvolvimento de projetos inovadores marcados pela racionalidade, padronização e economia, entre outros princípios [...]. Os gestores e profissionais que atuaram nestes órgãos acreditavam que os pressupostos defendidos pelos modernos poderiam gerar uma habitação econômica, vale dizer, com qualidade para atender dignamente o morador e barata o suficiente para ser alugada por um trabalhador de baixa renda. (BONDUKI, 2011, vol.1, p.96).

É particularmente a partir da atuação de profissionais encarregados pelos projetos dos conjuntos habitacionais, e, ainda, de gestores ligados à burocracia atuarial dos Institutos articulados com a preocupação estatal de estruturação de uma gama de direitos sociais, que é possível elucidar a aproximação entre o projeto moderno e a produção de moradias pelos diversos Institutos e Caixas. Um exemplo deste papel dos profissionais é dado pela obra do engenheiro-arquiteto Rubens Porto "O Problema das Casas Operárias e os Institutos de Aposentadoria e Pensões", de 1938, devido a sua colaboração para o programa habitacional dos IAP junto ao Ministério do Trabalho.

Naquele momento a arquitetura internacional preocupava-se com a resolução de um problema que persistia desde os primórdios da industrialização e se agravara após a Primeira Guerra Mundial: alojar as multidões que se aglomeravam nas cidades, sendo esta a razão social da arquitetura conforme arquitetos como Walter Gropius e Le Corbusier, cujas obras influenciariam significativamente o trabalho de Porto e de profissionais responsáveis pela elaboração dos projetos dos conjuntos residenciais dos IAP, tais como Carlos Frederico Ferreira, Eduardo Kneese de Mello e Attílio Corrêa Lima.

O novo governo, ao buscar uma identidade nacional representada por um país moderno e desenvolvido, portanto uma identidade a ser projetada e não recuperada do passado, criava as bases para o sentido do moderno no Brasil. Ao mesmo tempo, uma arquitetura nova e adaptada aos tempos industriais dava ao Estado um caráter modernizante e atualizado com o contexto internacional. Assim, profissionais que acreditavam no papel da arquitetura e do urbanismo modernos junto à sociedade, como Porto, compreenderam os conjuntos residenciais dos IAP como lugares onde poderiam concretizar os ideais de modernização e efetivação do papel social da arquitetura, atuando diretamente no projeto dos conjuntos habitacionais.

Foram previstos pelos diferentes Institutos de Aposentadoria e Pensões, ao todo, 36 conjuntos a serem empreendidos na então Grande São Paulo, com a construção de moradias para aluguel ou venda aos associados, sendo 32 deles 
construídos (BONDUKI, 2011). Dentre os conjuntos implantados seis se destacam pelas proporções e propostas de projeto, sendo possível enumerar algumas de suas características que se vinculam diretamente ao ideário moderno:

O Conjunto Residencial Várzea do Carmo (IAPI, 1938-42)(Figura 01) se destaca por: 1)proposição de habitação popular próximo ao centro/local de trabalho; 2) edifícios multifamiliares de apartamentos garantindo o adensamento populacional; 3) implantação dos edifícios sobre um grande plano arborizado associado ao uso do piloti; 4) atendimento a necessidades rotineiras para além da moradia, dado pelos equipamentos e serviços propostos; 5) preocupação quanto à insolação adequada das unidades.

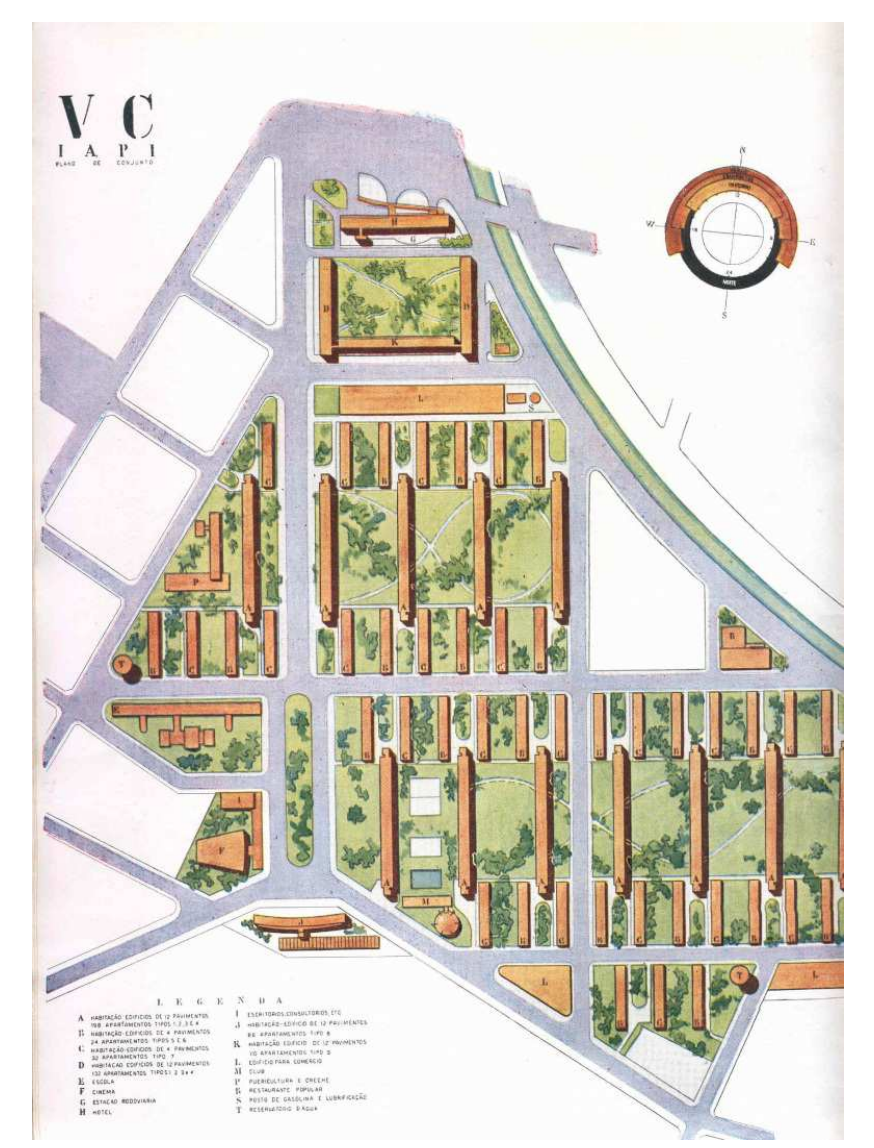

Figura 01: Planta original do C.R. Várzea do Carmo

Fonte: Revista Municipal de Engenharia, n.6, vol. IX, Nov.1942, p.7.

A região da Várzea do Carmo era em 1942 subutilizada, dado sua proximidade com diversos bairros operários, sua condição física sujeita a alagamentos, e ainda, seu alto valor imobiliário por estar nas imediações da área central, a despeito das tentativas de utilização da área em diversos momentos da urbanização paulistana. 0 projeto de Attilio Corrêa Lima, por princípio um conjunto de habitações populares, mais que a moradia, propunha garantir atividades de lazer, trabalho, serviço e estudo, 
buscando a integração social com outras classes, o que, devido a essas características, conferia àquele espaço uma proposta urbanística moderna, que buscava superar os obstáculos dados pelas questões do valor da terra e da estruturação social.

Também no Conjunto Residencial da Mooca (IAPI, 1946-49)(Figura 02) ressaltam características que se vinculam ao pensamento moderno: 1) habitação popular próxima ao local de trabalho; 2) edifícios multifamiliares de apartamentos garantindo o adensamento populacional; 3) implantação dos edifícios sobre um grande plano arborizado, aqui associado ao uso do piloti; 4) atendimento a necessidades rotineiras para além da moradia, dado pelos equipamentos e serviços propostos; 5) preocupação quanto à insolação adequada das unidades.

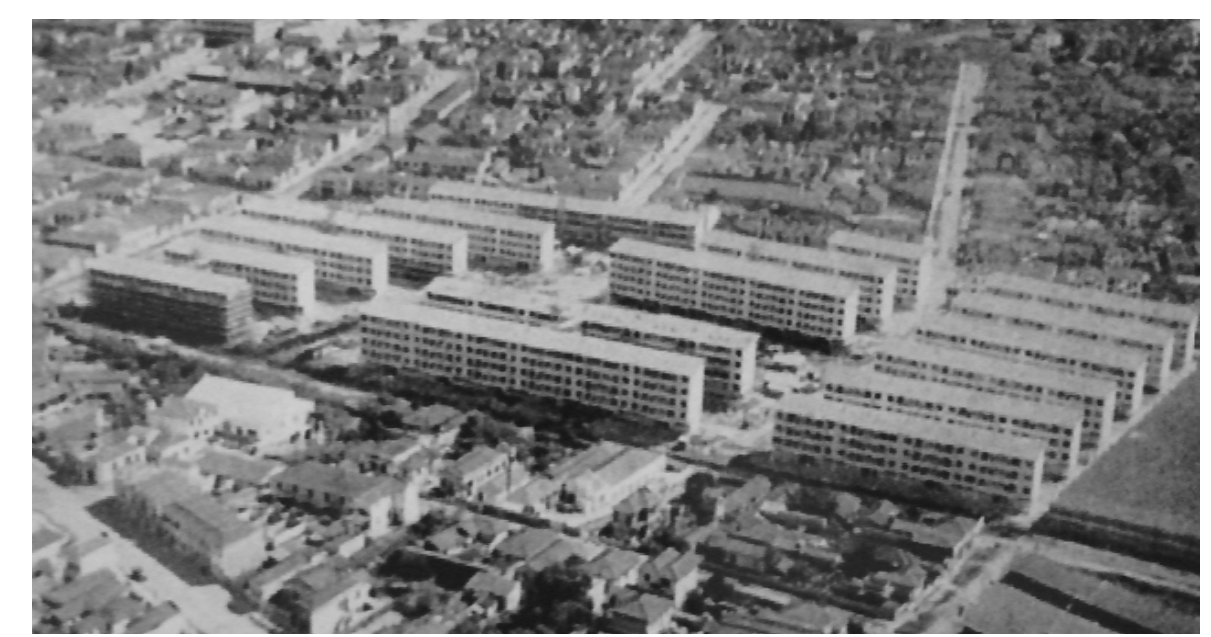

Figura 02: Vista do C.R. da Mooca logo após sua construção.

Fonte: BONDUKI, 2011, vol.2, p.47.

A Mooca já era bastante ocupada na região próxima ao centro da cidade e ao entroncamento ferroviário entre a São Paulo Railway e a E. F. Central do Brasil, principalmente por galpões e armazéns industriais, sendo essa região favorecida ainda pelo transporte através de bondes elétricos. Quanto mais distante do centro mais parcamente urbanizado era o bairro, embora já contando com algum tipo de arruamento, sendo ocupado majoritariamente por moradias operárias. Dada a existência das ferrovias, era natural que a região fosse visada pelas indústrias e natural também era que os operários procurassem se instalar próximo a estes locais, que, no entanto, padeciam da falta de residências adequadas em termos sanitários, da falta de infraestrutura e meios de transporte. O projeto de Paulo Antunes Ribeiro não propunha a conformação de um centro regional como o C. R. Várzea do Carmo, mas dentro da política habitacional do IAPI buscava atender à necessidade por 
moradia próxima aos locais de trabalho de seus associados, constituindo na Mooca um núcleo habitacional de qualidade tanto no aspecto construtivo e sanitário, quanto em termos sociais e culturais, que em muito superava as vilas operárias construídas no bairro pelo setor privado.

No Conjunto Residencial Vila Guiomar (IAPI, 1942-53)(Figura 03) o ideário moderno está presente 1) ao proporcionar habitação popular próxima a locais de trabalho; 2) na opção por edifícios multifamiliares de apartamentos garantindo o adensamento populacional; 3) na implantação dos edifícios sobre um grande plano arborizado associado ao uso do piloti; 4) na utilização de unidades unifamiliares isoladas associadas a conceitos como vias de serviço e ruas curvilíneas; 5 ) no respeito à configuração do sítio; 6) no atendimento a necessidades rotineiras para além da moradia, dado pelos equipamentos propostos; 7) na preocupação quanto à insolação adequada das unidades.

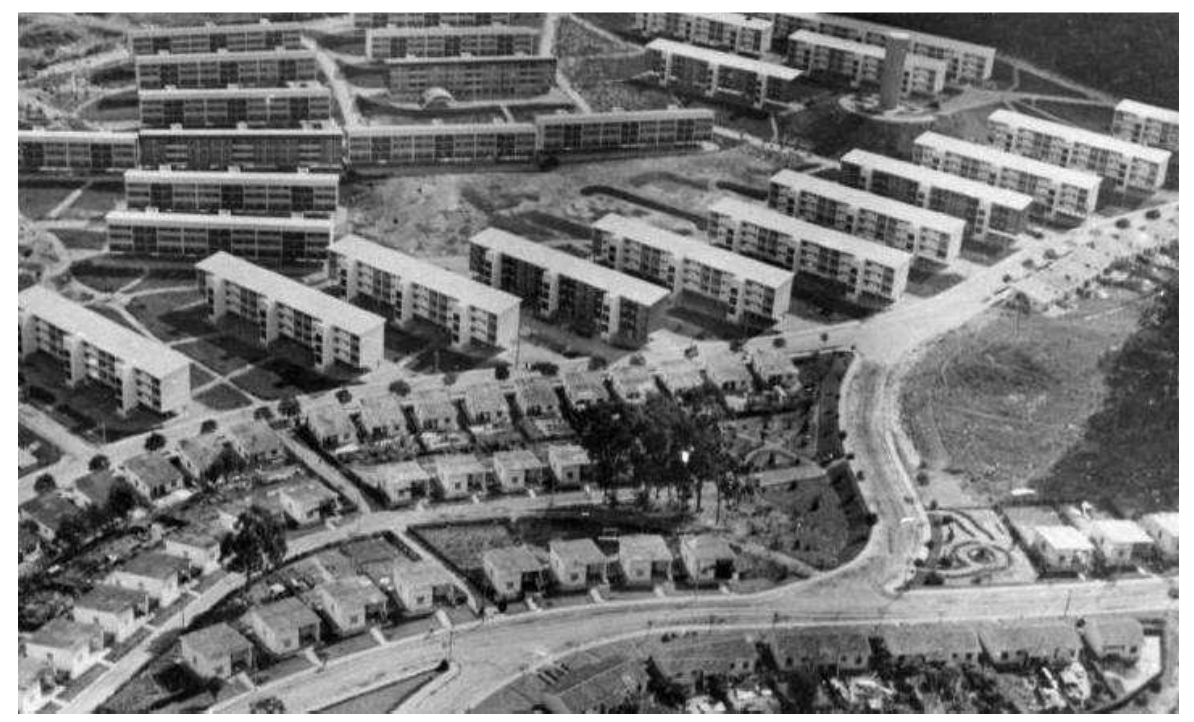

Figura 03: Vista Parcial do Conjunto Residencial Vila Guiomar, 1940.

Fonte: PESSOLATO, C. Conjunto IAPI Vila Guiomar-Santo André-SP: Projeto e História. Dissertação, FAU-USP, São Paulo, 2007, p.126.

A região de Santo André, onde é construído o conjunto, associava amplamente a presença da ferrovia e do rio Tamanduateí à atividade industrial, que aí se desenvolveu perifericamente à cidade de São Paulo. A proposta de habitação popular atendia à necessidade de moradia por parte dos industriários da região, com a possibilidade de morarem próximos de seus locais de trabalho. A gleba imensa tratada e urbanizada, com grande densidade populacional, porém sem perder qualidade ambiental e social, demonstra o pioneirismo do IAPI e de Carlos Frederico Ferreira ao propor este conjunto numa área ainda em plena expansão urbana. 
Quando comparado a outros empreendimentos residenciais dos IAP, tais como o Vila Guiomar ou o conjunto do IAPI na Mooca, ressaltam no Conjunto Residencial da Mooca (1946-49) do IAPETC (Figura 04) conceitos ainda tradicionais em sua arquitetura, como a cobertura em telha cerâmica ou a multiplicidade de pequenas esquadrias. Entretanto, quando se trata dos princípios urbanísticos aqui presentes, 0 conjunto projetado por Eurico Guimarães se vincula de maneira definitiva ao urbanismo moderno nas seguintes características: 1) proposição de habitação popular próximo aolocal de trabalho; 2) respeito à configuração do sítio; 3) edifícios multifamiliares de apartamentos garantindo o adensamento populacional; 4) implantação dos edifícios sobre um grande plano comum; 5) opção por unidades unifamiliares em renque associadas a conceitos como vias de serviço.

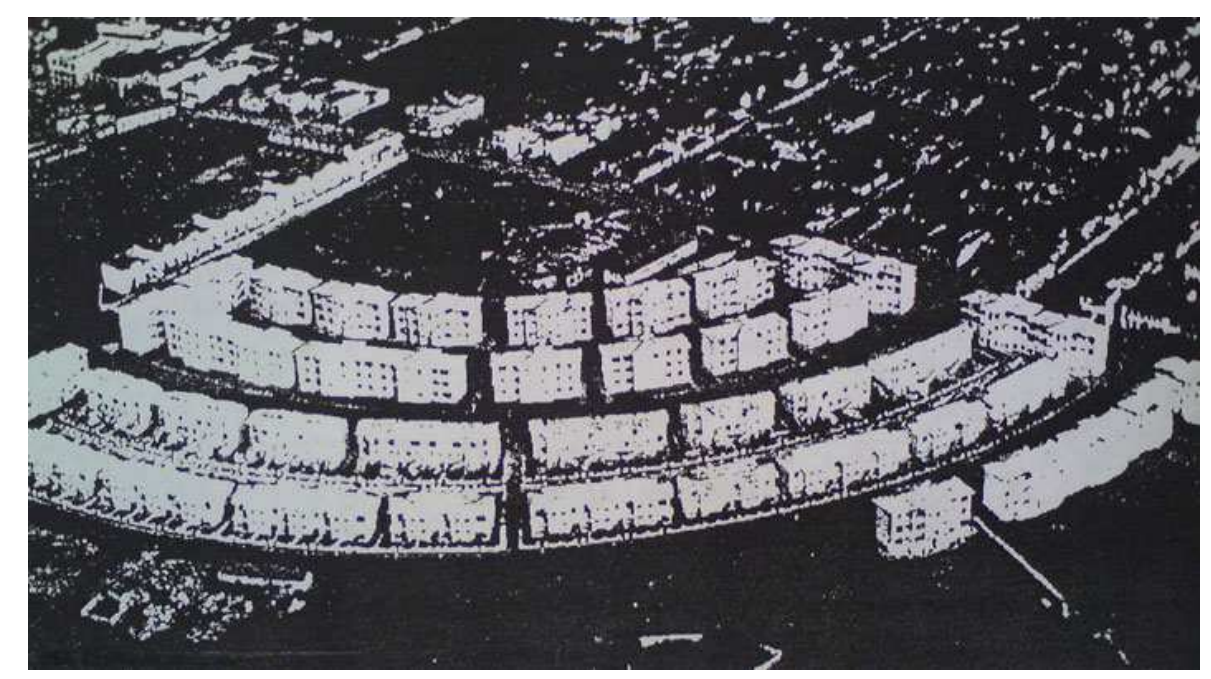

Figura 04: Vista do C.R. da Mooca.

Fonte: BRUNA, P. Os Primeiros Arquitetos Modernos: Habitação Social no Brasil 1930-1950. Livre-Docência. FAU-USP, São Paulo, 1998, p.186.

Ainda uma vez analisando o bairro da Mooca em sua porção mais distante da área central da cidade, onde se viam mais moradias operárias que galpões industriais, e considerando a condição da falta de residências adequadas em termos sanitários, da falta de infraestrutura e meios de transporte que ligassem adequadamente o bairro ao centro, podemos admitir o conjunto do IAPETC como um ponto de destaque em meio à urbanização do bairro. O projeto, além de oferecer moradias populares de qualidade construtiva e sanitária adequadas e próximas a locais de trabalho dos associados, propiciou o adensamento daquela área em que se inseriu e, se supõe, um tipo de sociabilização diferenciada pela criação de um setor segregado, dado seu arruamento 
destoante do entorno, com aproveitamento do relevo natural do sítio, e pelo tratamento dos espaços livres do conjunto.

Sendo o Conjunto Residencial Santa Cruz (1948-49)(Figura 05), como afirma Bonduki (2011), representante do momento em que o IAPB deixava de construir conjuntos constituídos apenas por unidades unifamiliares isoladas, com técnicas e desenhos tradicionais, e passava a demonstrar a preocupação em ampliar os serviços oferecidos aos associados para além da moradia, importando também espaços de lazer, áreas livres e equipamentos comunitários, seu enquadramento nos princípios do pensamento moderno se reflete: 1 ) na opção por edifícios multifamiliares de apartamentos garantindo o adensamento populacional; 2) na implantação dos edifícios sobre um grande plano comum arborizado; 3) no atendimento a necessidades rotineiras para além da moradia, dado pelos equipamentos e serviços propostos; 4) na preocupação quanto à insolação adequada das unidades; 5) na hierarquização viária.

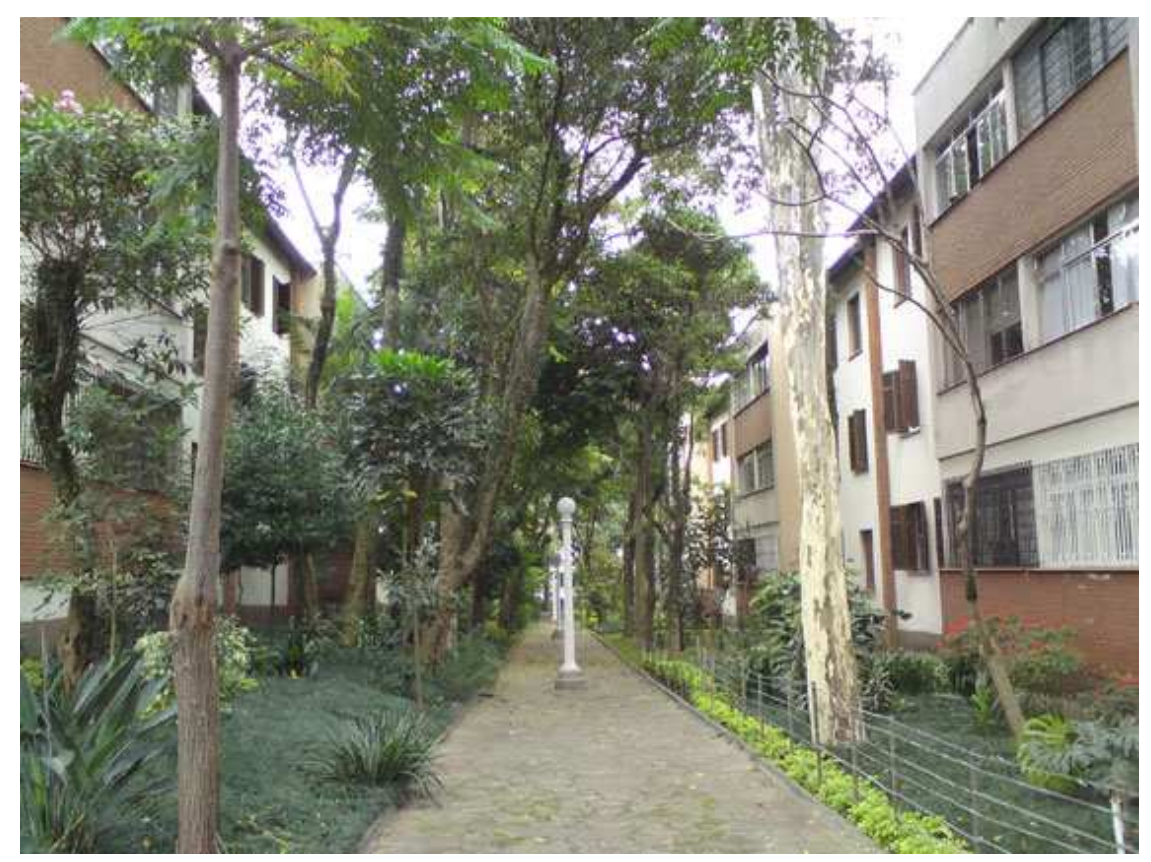

Figura 05: Via exclusiva de pedestres em meio a área verde.

Fonte: Fotografia de Camila Ferrari, maio, 2012.

É preciso considerar que a região em que está o conjunto era praticamente desocupada na época de sua implantação e continuaria assim até pelo menos a década de 1950, abrigando chácaras, parques e hospitais. Assim sendo, o projeto de Marcial Fleury de Oliveira é pioneiro ao propor a habitação popular no local e associála à urbanização daquele setor da cidade, superpondo a preocupação social à especulação imobiliária e, ainda, garantindo a esta população áreas livres com 
tratamento diferenciado, que possibilitaram a sociabilização entre os moradores, fato constatado ainda atualmente pela utilização das áreas livres comuns.

Mais uma vez tendo em mente a preocupação do IAPB em garantir a habitação popular associada a projetos urbanísticos racionalizados, é possível enumerar características do Conjunto Residencial Santo Antonio (196267)(Figura 06), projeto de R. Betelman e N. Barbieri, que se vinculam ao pensamento moderno: 1) a opção por edifícios multifamiliares de apartamentos garantindo o adensamento populacional; 2) a implantação dos edifícios sobre um grande plano comum arborizado; 3) o atendimento a necessidades rotineiras para além da moradia, dado por equipamentos e serviços propostos 4) a preocupação quanto à insolação adequada das unidades; 5) o respeito à configuração do sítio.

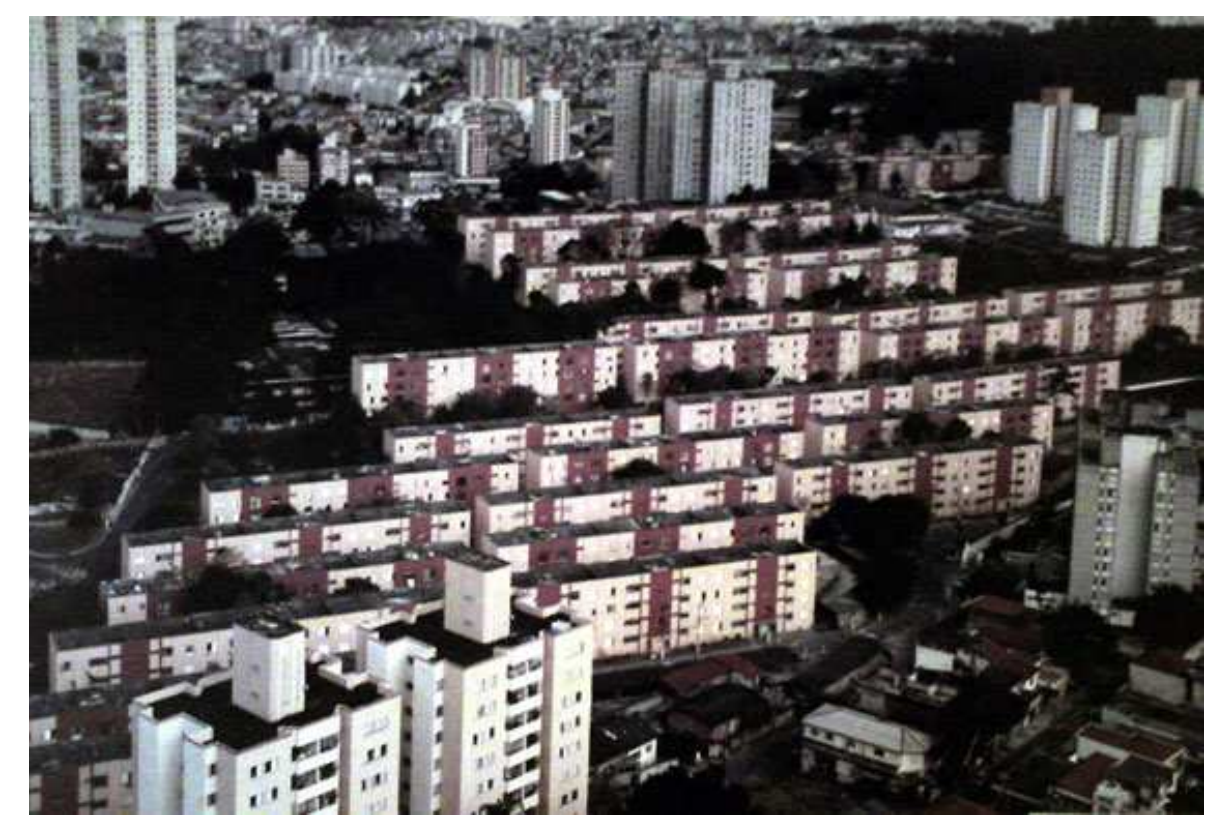

Figura 06: Foto aérea do C.R. Santo Antonio.

Fonte: Acervo Condomínio Santo Antonio. Jul. 2003

A implantação do C.R. Santo Antonio foi também anterior à ocupação e adensamento do bairro que, assim como o Bosque da Saúde, onde estava o C.R. Santa Cruz, abrigava chácaras e hospitais, dados seu clima e altitude, buscados pela elite paulistana. Sendo assim, o IAPB é novamente pioneiro ao propor a habitação popular no local e associá-la à urbanização deste setor da cidade que abrigou um dos maiores conjuntos dos IAP e, mais uma vez, demonstrando a atenção à questão social da moradia presente nos Institutos.

De acordo com a análise, os conjuntos habitacionais dos Institutos de Aposentadoria e Pensões se apresentavam, portanto, como projetos de habitações 
populares que incorporavam preceitos do ideário moderno, fosse pela política particular das divisões de engenharia dos diferentes IAP, fosse pelo engajamento dos profissionais responsáveis pelos projetos. Contudo, mais que incorporar questões sanitárias, de circulação, ambientais e funcionais, ao mesmo tempo em que constroem moradias estes conjuntos habitacionais produzem também cidade, e uma cidade cuja questão central é a habitação popular, a base do urbanismo moderno através da qual desde o século XIX se procurava criar novos espaços que superassem os resultados negativos da industrialização quanto à moradia do trabalhador.

\section{Conclusões}

Entendemos que em São Paulo, sítio de inúmeros planos de melhoramentos, apesar do desenvolvimento de uma incipiente industrialização e de condições de degradação urbana e sanitária, bem como de falta de moradia, semelhantes àquelas das metrópoles industriais europeias do início do século XIX, pontos-chave de concepções urbanística realizadas desde a Revolução Industrial, tais como o fim da a integração entre classes sociais distintas ${ }^{3}$, pouco representavam para o cenário da urbanização paulistana.

Configurava-se, portanto, uma apropriação apenas parcial dos elementos do urbanismo moderno, em que justamente a problemática social permanecia excluída das pautas de intervenção estatal. Noções como o zoneamento, a racionalidade da circulação viária e o higienismo, e mesmo aspectos sociais como a garantia à educação, perpassavam os planos de melhoramentos urbanos sem, contudo, pretender solucionar aquela que era a questão central nos projetos de cidades modernas, ou seja, a habitação. Assim sendo, nos apoiando em autores como Campos, Somekh e Gorelik ao tratar da urbanização paulistana desde finais do século XIX até início do século $X X$, sugerimos a permanência de uma aspiração ao moderno que tentou implantar o urbanismo modernizador em um quadro que, contudo, se configurava conforme a especulação imobiliária e as relações de dominação no interior da estrutura social paulistana, dificultando ações mais diretamente relacionadas ao projeto moderno de cidade.

A partir de 1937 as circunstâncias econômicas e sociopolíticas brasileiras seriam redirecionadas pelo governo nacional nos moldes do Estado Novo, com foco no desenvolvimento nacional através da industrialização e na admissão do trabalhador

\footnotetext{
${ }^{3}$ Sobre este assunto ver SINGER, Paul. Economia Política da Urbanização. 5. ed. São Paulo:Brasiliense, 1978.
} 
nacional como base dessa indústria, conferindo direitos trabalhistas e sociais antes negados ao operariado. Nessa conjuntura se inserem os IAP como órgãos que garantiriam tais direitos aos trabalhadores associados, entre eles a assistência médica e a habitação. O quadro da urbanização paulistana era, porém, muito próximo daquele anterior ao Golpe de 1930, considerando-se que persistiam os entraves à modernização plena dados, principalmente, por interesses relacionados ao valor e à propriedade da terra urbana e pela manutenção de posições na estrutura social.

Nos conjuntos projetados sob os auspícios dos Institutos para a então Grande São Paulo, não obstante, se demonstrava a preocupação em garantir a moradia racionalizada e saudável, bem como o acesso à cidade e ao local de trabalho, a equipamentos comunitários, áreas verdes e vida em sociedade e, ainda, a uma nova dimensão social dada não apenas pela qualidade projetual e construtiva desses empreendimentos, mas também pela sua localização no espaço urbano e pela proposta de abrigar em um mesmo ambiente diferentes hierarquias de trabalhadores. Essas eram características comuns a grande parte dos conjuntos que revelavam uma vinculação ao ideário moderno não só de arquitetura, mas também de cidade e sociedade, por parte dos responsáveis por esses projetos, fossem os próprios IAP como provedores, fossem os profissionais de arquitetura e urbanismo envolvidos.

A produção habitacional dos IAP - e de outros órgãos que naquele momento construíram moradias populares, como a Fundação da Casa Popular e o Departamento de Habitação Popular do Distrito Federal - se apresenta como uma oportunidade para profissionais que se coadunavam com o Movimento Moderno de projetar e construir a arquitetura e a cidade modernas, baseados em novas técnicas e novas proposições sociais, com foco na moradia como geradora de projetos urbanos. Entendemos que o papel desses profissionais, entre os quais destacamos Attilio Corrêa Lima, Eduardo Kneese de Mello e Carlos Frederico Ferreira, que desde antes de sua vinculação aos IAP já procuravam inserir em seus trabalhos o ideário moderno, é fundamental para a compreensão da utilização desses princípios nos projetos residenciais dos vários Institutos, junto aos quais produziriam conjuntos habitacionais onde seria possível demonstrar o projeto moderno na íntegra, sem o tolhimento dado por condições de especulação imobiliária e segregação socioespacial.

Mesmo que grande parte dos conjuntos habitacionais dos IAP não tenha sido implantada exatamente como fora previsto em projeto, em sua concepção, mais que uma aspiração ao moderno estava presente o ideal de modernização constante na concepção de Campos (2002, p.25) como "as múltiplas transformações sociais, econômicas, demográficas, culturais, comportamentais, institucionais e políticas que 
acompanham o processo de implantação do modo de produção capitalista e as novas realidades e relações resultantes", em que se reconhecem elementos essenciais do projeto de cidade moderna como a habitação, a vida em comunidade e a integração das classes trabalhadoras.

Dentro de nossa proposição, consideramos que entre 1933 e 1964, a atuação dos Institutos na então Grande São Paulo através da produção de habitações caracterizou um momento em que, a despeito da simples aspiração ao moderno que regulava a urbanização paulistana geral, a própria produção de cidade se deu como um processo de modernização de fato, abarcando a função social da arquitetura definida pelo alojamento.

Essas ações permaneceram, entretanto, como projetos pontuais no espaço urbano paulistano, que se expandia vertical e horizontalmente, através de novos edifícios e loteamentos que seguiam controlados pela especulação imobiliária e pela manutenção de históricas relações de dominação na estrutura social e na localização dos investimentos.

O debate sobre nossa suposição inicial, de que os conjuntos habitacionais dos IAP implantados na Grande São Paulo, para além da habitação constituíram também projetos de cidades modernas, não se esgota neste trabalho. No entanto, os dados levantados corroboram nossa proposição ao demonstrar que a despeito da urbanização paulistana que se fazia sob uma aspiração ao moderno, nos conjuntos dos IAP se manifestavam questões sociais abstraídas pelos planos de melhoramentos, tais como a integração social dos trabalhadores e a ocupação de áreas inteiras com moradias como base de planos urbanizadores, vinculando, portanto, estes projetos de habitação popular ao projeto moderno de cidade.

\section{Referências}

BONDUKI, N.G. Origens da Habitação Social no Brasil: Arquitetura Moderna, Lei do Inquilinato e Difusão da Casa Própria. São Paulo: Estação Liberdade/FAPESP, 1998.

BONDUKI, N.G. Pioneiros da habitação social no Brasil. Tese de Livre-Docência. FAU-USP, São Paulo, 2011. Vol. 1 e 2 .

CAMPOS, C. M. Os Rumos da Cidade: Urbanismo e Modernização em São Paulo. São Paulo: SENAC, 2002.

GORELIK, A. "O moderno em debate: cidade, modernidade e modernização" In: MIRANDA, W. M. (Org.). Narrativas da modernidade. Belo Horizonte: Autêntica, 1999, p.55-80. 
LEME, M. C. (Org.) Urbanismo no Brasil 1895-1965. São Paulo:Studio Nobel/ FAUUSP/ FUPAM, 1999.

MAIA, P. Introdução ao estudo de um plano de avenidas para a cidade de São Paulo. Prefeitura de São Paulo - Comissão do Tietê. São Paulo: Companhia Melhoramentos de São Paulo, 1930.

MORSE, R. Formação Histórica de São Paulo: de Comunidade à Metrópole. São Paulo:Difusão Européia do Livro, 1970.

SAMPAIO, M. R. A. (Coord.). São Paulo 1934-1938: Os anos da Administração Fabio Prado. São Paulo: FAU-USP, 1999.

SIMÕES JUNIOR, J. G. "O setor de obras públicas e as origens do urbanismo na cidade de são Paulo" In: Espaço e debates. Revista de Estudos Regionais e Urbanos. Cidade e História, Ano XI, n. 34, 1991. p. 71-74.

SOMEKH, N.; CAMPOS, C. M. "Plano de avenidas: o diagrama que se impôs" In: SOMEKH, N.; CAMPOS, C. M. (org.) A Cidade que não pode parar: Planos urbanísticos de São Paulo no século XX. São Paulo: Mack Pesquisa, 2002. p.5572.

WefFort, F. O Populismo da Política Brasileira. Rio de Janeiro:Paz e Terra, 1980. 